\title{
Nappe Flow Surges down a Rough-Stepped Sloping Channel
}

\author{
Fengguang Yang ${ }^{1}$; Vijay P. Singh, Dist.M.ASCE²; Xiekang Wang ${ }^{3}$; and Xingnian Liu ${ }^{4}$
}

\begin{abstract}
Nappe flow applies to small discharges, and investigation of nappe flow surges helps to understand the mechanism of water flow in stepped open channels. The objective of this paper is to investigate the nappe flow surge propagation down stepped open channels. First, an analytical solution of dam-break shock waves or flood waves is derived. Then, the theoretical solution is used to calculate the wavefront and celerity and is verified using experiments on surging waters down a stepped slope in a 20-m-long and 0.5-m-wide open channel under three conditions: one for smooth bed surface and the others for rough bed surface glued with uniform sediment (of diameter $d_{s}=1.715 \mathrm{~mm}$ and $d_{s}=3.5 \mathrm{~mm}$ ). For calculating the wavefront propagation in a stepped open channel, a formula for resistance, composed of grain resistance and step geometry resistance, is developed. Unlike skimming flow, the roughness of step surface in the nappe flow regime influences the friction factor $f_{s}$. Results show that the friction factor increases with the relative roughness height $\left(d_{s} / d_{0}\right)$. The theoretical solution for the wavefront location and celerity is then revised by combining the friction formula, and the revised solution is tested for a wide range of experimental data. Test results show that the revised solution fits the measured data quite well. Comparing with the solution previously derived, the revised solution derived in this study more accurately predicts the wavefront location and celerity for the nappe flow condition. DOI: 10.1061/(ASCE)HE.1943-5584.0001570. () 2017 American Society of Civil Engineers.
\end{abstract}

Author keywords: Nappe flow; Stepped slope; Darcy-Weisbach friction factor; Dam break equation.

\section{Introduction}

Stepped channels have been designed for more than 3,500 years. Greek and Minoan engineers were probably the first to design an overflow stepped weir and stepped storm waterways, respectively (Chanson 2002). Later, Roman, Muslim, Mughal, and Spanish engineers employed similar designs. The rough or stepped face of a stepped channel can dissipate a significant portion of energy of the flow over its surface. The dissipation of kinetic energy reduces the scour in the natural channel below the structure and hence the cost of the stilling basin (Tabbara et al. 2005; Simoes 2010; Zare and Doering 2012).

Stepped channel hydraulics are complicated because of different flow regimes, but most importantly, because of strong flow aeration, very-strong turbulence, and interaction between entrained air and turbulence (Chanson and Toombes 2002). For a given stepped channel, water flows as a succession of free-falling nappes (nappe

${ }^{1}$ Associate Professor, State Key Laboratory of Hydraulics and Mountain River Engineering, Sichuan Univ., Chengdu 610065, China (corresponding author). E-mail: 27521656@qq.com

${ }^{2}$ University Distinguished Professor and Regents Professor, Dept. of Biological and Agriculture Engineering, and Zachry Dept. of Civil Engineering, Caroline and William N. Lehrer Distinguished Chair in Water Engineering, Dept. of Biological and Agriculture Engineering, Texas A\&M Univ., College Station, TX 77843-2117. E-mail: vsingh@tamu.edu

${ }^{3}$ Professor, State Key Laboratory of Hydraulics and Mountain River Engineering, Sichuan Univ., Chengdu 610065, China. E-mail: wangxiekang@ scu.edu.cn

${ }^{4}$ Professor, State Key Laboratory of Hydraulics and Mountain River Engineering., Sichuan Univ., Chengdu 610065, China. E-mail: liuxingnian@ 126.com

Note. This manuscript was submitted on October 15, 2015; approved on April 20, 2017; published online on July 22, 2017. Discussion period open until December 22, 2017; separate discussions must be submitted for individual papers. This paper is part of the Journal of Hydrologic Engineering, (C) ASCE, ISSN 1084-0699. flow regime) at small discharges (Chamani and Rajaratnam 1994; Chanson 1994a, b). There are many natural instances of falls in mountainous terrains, such as the Rocky Mountains in the United States, where such flows occur. For large flows, skimming over the pseudoinvert is formed by step edges, i.e., the skimming flow regime (Rajaratnam 1990; Chamani and Rajaratnam 1999a, b; Chanson 2004a, b; Meireles and Matos 2009). For an intermediate range of flow rates, a transition flow regime is observed (Chanson and Toombes 2004; Sanchez and Dolz 2005).

Most prototype spillways operate at large discharges per unit width (i.e., skimming flow regime) for which the waters skim as a coherent stream over the pseudobottom formed by step edges, so it is not surprising that most previous researchers have focused on that regime. Skimming flows are characterized by very significant form losses and momentum transfer from the main stream to the recirculation zones (Rajaratnam 1990; Chamani and Rajaratnam 1999a, b; Chanson et al. 2002; Meireles and Matos 2009). In a skimming flow regime, the steps act as large roughness elements and most of the energy is dissipated to maintain stable horizontal vortices beneath the pseudobottom formed by the external edges of the steps. The vortices are maintained through the transmission of turbulent shear stress between the skimming stream and the recirculating fluid underneath.

Chanson (2004b) conducted flume experiments to investigate the flood wavefront location and celerity, and proposed a semiempirical equation relating the dimensionless wavefront location and celerity to the dimensionless time using Hunt's (1982) theory. Fig. 1 presents the range of prediction error for which the data and equations were presented previously by Chanson (2004b) and the difference between prediction and measurement was defined as

$$
\text { Error }=\frac{\mid \text { Prediction }- \text { measurement } \mid}{\text { Measurement }}
$$

With the use of the original Chanson (2004b) solution, the wavefront location is predicted with an average error of $52.6 \%$ 

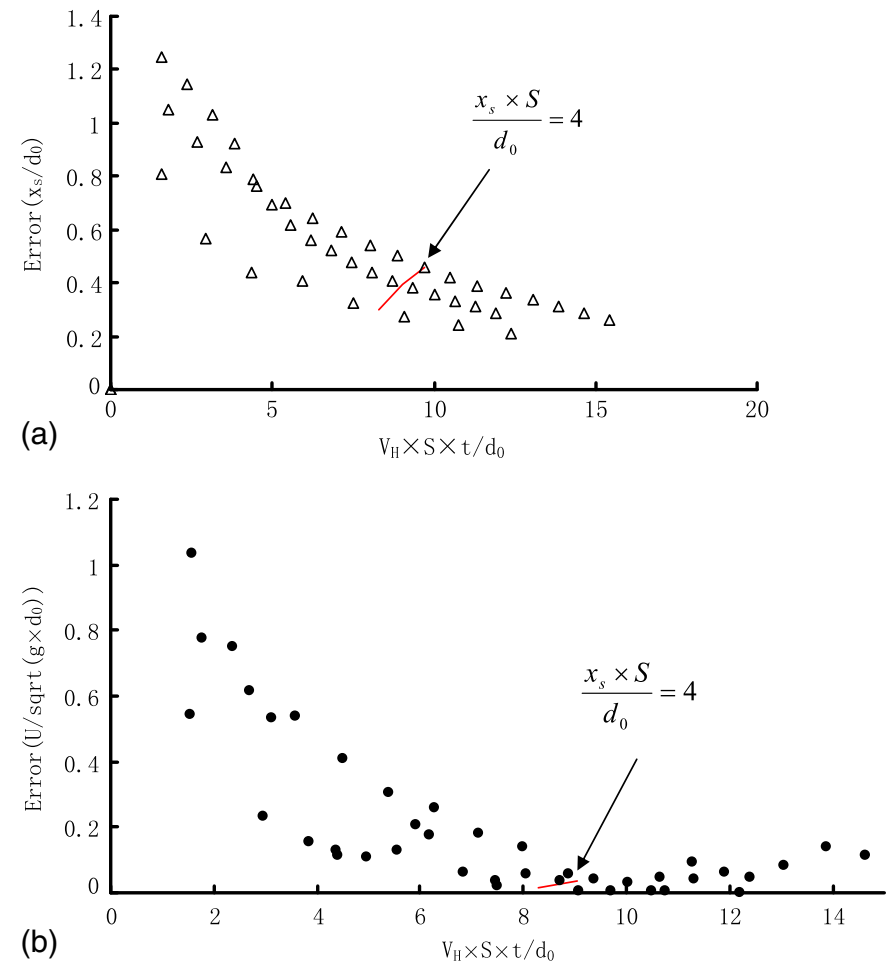

Fig. 1. Range of prediction error varying with dimensionless time for (a) flood wavefront location; (b) flood wavefront celerity (data from Chanson 2004b)

and can be overestimated by as much as $124.7 \%$; similarly, the wavefront celerity is predicted with an average error of $26.2 \%$ and the maximum error can go as high as $62.5 \%$. Chanson explained that his model was only valid if the wave had traveled more than four times, e.g., $x_{s} S / d_{0}>4$, where $x_{s}$ is the dam break wave or flood wave traveling distance, $S$ is the bed slope, and $d_{0}$ is the reservoir height at the dam site. The right part of the line in Fig. 1 shows the region of validity of his model, and even then the maximum error can be up to 45.5 and $13.7 \%$ in the prediction of flood wavefront location and celerity, respectively. Additionally, his study is limited in scope because it considered (1) a smooth bed surface, (2) a constant value of Darcy-Weisbach resistance factor $f_{s}=0.05$, and (3) limitation of $x_{s} S / d_{0}>4$. Further, Chanson (2004b) provided little information of $f_{s}$ on the nappe flow surge down a stepped sloping chute system.

Nappe flow is characterized by a series of free-falling jets with nappe impact onto the downstream step. Here normally small discharges are involved. The flow energy is dissipated by jet breakup in air, jet impact and mixing on the step, and the formation of a hydraulic jump on the step. Studying the nappe flow surges helps understand the mechanism of water flow in stepped open channels.

The preceding discussion suggests that a further study of nappe flow surge propagation is needed. Unlike skimming flow, the roughness condition of the step surface may influence the nappe flow surge propagation. Therefore, this study is an extension of the studies by Hunt (1982) and Chanson (2004b) and focuses on the nappe flow condition. The objectives of this study therefore were (1) to derive an analytical solution of the ordinary differential equation developed by Hunt (1982); (2) to develop a parsimonious relation that may be used to predict the DarcyWeisbach resistance factor $f_{s}$ for nappe flow regime and all bed surface conditions of the stepped sloping open channels; (3) to complete the experimental study of Chanson by extending the

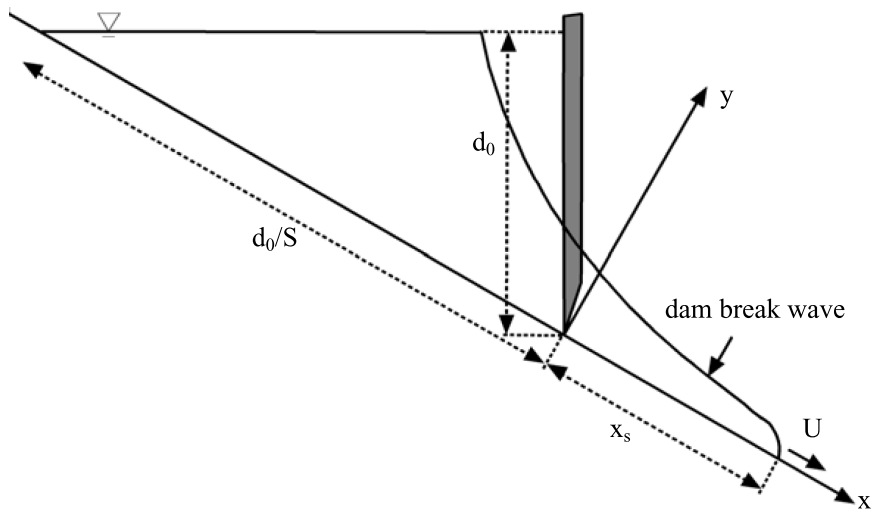

Fig. 2. Dam break wave on a sloping channel

bed conditions to rough step surface in the nappe flow regime; and (4) to derive revised solutions developed in Objective 1 for computing the wavefront location and celerity of smooth and rough stepped open channels for nappe flows using laboratory experiments.

\section{Theory}

Hunt (1982) derived a solution for flood waves resulting from the complete and instantaneous collapse of a dam by using the kinematic-wave approximation. For a prismatic rectangular channel, Hunt's solution yields

$$
\frac{d x^{*}}{d t^{*}}=-\frac{3}{4} t^{*}+\sqrt{x^{*}+\left(\frac{3}{4} t^{*}\right)^{2}}
$$

in which $x^{*}$ and $t^{*}$ are both dimensionless variables expressed as

$$
\left(x^{*}, t^{*}\right)=\left(\frac{S \times x_{s}+d_{0}}{d_{0}}, \frac{V_{H} \times S \times t}{d_{0}}\right)
$$

where $t=$ time with $t=0$ at dam break; $x_{s}=$ dam break wavefront position measured from the dam site; and $S=$ bed slope. The reservoir height at the dam site $d_{0}$ can be expressed as (Montes 1998)

$$
d_{0}=\frac{9}{4} \sqrt[3]{\frac{Q^{2}}{g \times b^{2}}}
$$

in which $Q=$ initial flow rate; $b=$ channel width; and $g=$ gravitational acceleration. In fact, $d_{0}$ should be the initial reservoir water depth for a surge propagation down an initially dry channel; all the variables are shown in Fig. 2. The uniform equilibrium flow velocity is defined as

$$
V_{H}=\sqrt{\frac{8 g}{f_{s}} \times d_{0} \times S}
$$

in which $f_{s}=$ Darcy-Weisbach friction factor for stepped open channel flow, which will be analyzed in the next section.

Eq. (2) is a kind of implicit differential equation (Walter 1998) whose solution can be expressed as

$$
x^{*}=-\frac{9}{16} t^{* 2}+f^{2}\left(t^{*}\right)
$$

where $f\left(t^{*}\right)=$ function of $t^{*}$ and can be expressed as 


$$
C_{1}=\left[f\left(t^{*}\right)+\frac{1}{4} t^{*}\right]\left[f\left(t^{*}\right)-\frac{3}{4} t^{*}\right]^{3}
$$

where $C_{1}=$ constant. Hunt (1982) gave only the analytical results of Eq. (2); a detailed description is listed in the Appendix. With the use of Eq. (3), Eqs. (2), (6), and (7) can be further rewritten, respectively, in dimensional form as

$$
\begin{aligned}
\frac{U}{V_{H}}=-\frac{3}{4} \times \frac{V_{H} \times S \times t}{d_{0}}+\sqrt{1+\frac{S \times x_{s}}{d_{0}}+\left(\frac{3}{4} \times \frac{V_{H} \times S \times t}{d_{0}}\right)^{2}} \\
\frac{S \times x_{s}}{d_{0}}=-\frac{9}{16}\left(\frac{V_{H} \times S \times t}{d_{0}}\right)^{2}+f^{2}\left(\frac{V_{H} \times S \times t}{d_{0}}\right)-1 \\
C_{1}=\left[f\left(\frac{V_{H} \times S \times t}{d_{0}}\right)+\frac{1}{4} \times \frac{V_{H} \times S \times t}{d_{0}}\right] \\
\times\left[f\left(\frac{V_{H} \times S \times t}{d_{0}}\right)-\frac{3}{4} \times \frac{V_{H} \times S \times t}{d_{0}}\right]^{3}
\end{aligned}
$$

where $U=d x_{s} / d t=$ wavefront celerity.

The relationship of $f\left(t^{*}\right)$ as a function of $t^{*}$ is plotted for various values of $C_{1}$ in Fig. 3, which is computed using Eq. (10) for $C_{1}=0, \pm 1, \pm 5$, and \pm 20 . The figure shows that for given constant $C_{1}$, the relationship between $f\left(t^{*}\right)$ and $t^{*}$ can be determined. From Eq. (11) and Fig. 3, it can also be found that the dimensionless parameter $t^{*}$ and $f\left(t^{*}\right)$ should always be positive and the $f\left(t^{*}\right)$ value increases with $t^{*}$ for a given $C_{1}$.

It is reasonable to assume that the dam break wavefront position $x_{s}$ should be positive for $t \geq 0$. Then, using Eq. (9) gives

$$
f\left(t^{*}\right) \geq \sqrt{\left(\frac{3}{4} t^{*}\right)^{2}+1} \geq \frac{3}{4} t^{*}
$$

Eq. (11) gives $f\left(t^{*}\right) \geq 3 t^{*} / 4$ as the lower limit; if $f\left(t^{*}\right)$ is smaller than this lower limit, the wavefront position may be negative for $t^{*} \geq 0$ and that condition cannot be explained physically (Fig. 3). The initial condition can be expressed as that the wavefront position $x_{s}$ measured from the dam site is zero with $t=0$.

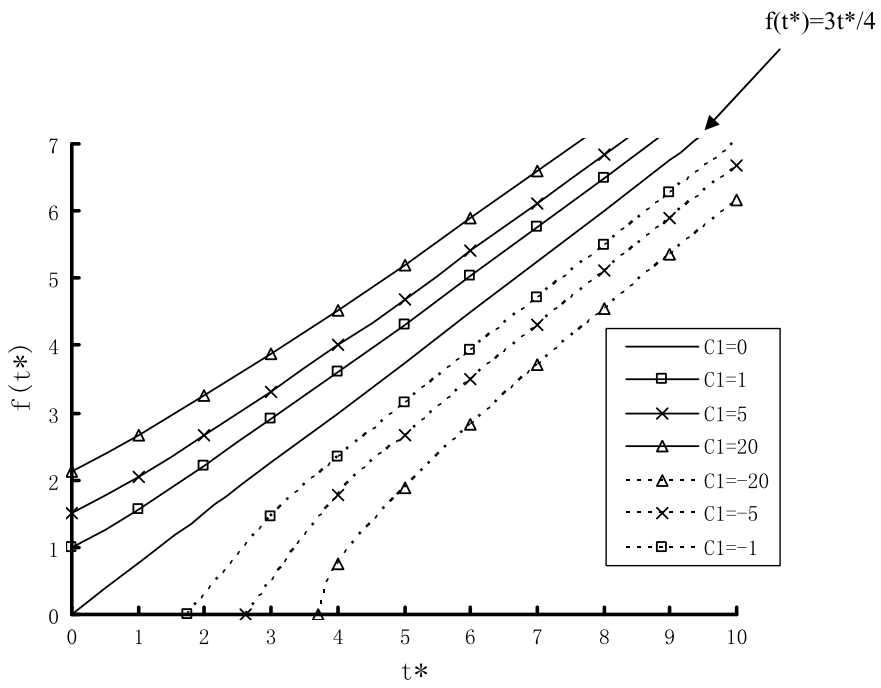

Fig. 3. Variations of function $f\left(t^{*}\right)$ with dimensionless $t^{*}$ and constant $C_{1}$

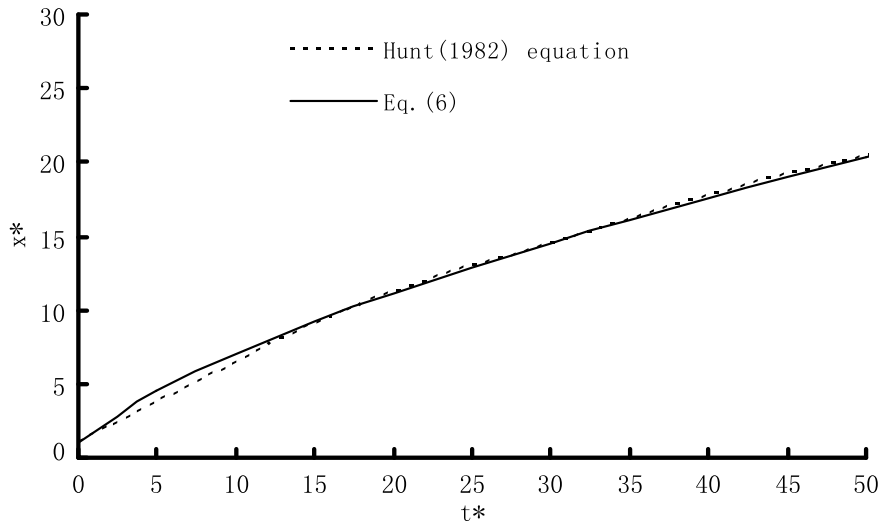

Fig. 4. Comparison between theoretical solution of Eq. (2) and Hunt's (1982) asymptotic solution

Therefore, at the initial condition, Eq. (9) can be expressed in the following form:

$$
f(0)=1
$$

Substituting Eq. (12) into Eq. (10) yields

$$
C_{1}=1
$$

Combining Eqs. (10) and (13) gives

$$
\begin{aligned}
& {\left[f\left(\frac{V_{H} \times S \times t}{d_{0}}\right)+\frac{3}{4} \times \frac{V_{H} \times S \times t}{d_{0}}\right]} \\
& \quad \times\left[f\left(\frac{V_{H} \times S \times t}{d_{0}}\right)-\frac{1}{4} \times \frac{V_{H} \times S \times t}{d_{0}}\right]^{3}=1
\end{aligned}
$$

Eqs. (8) and (9), together with Eq. (14), can be used to calculate the wavefront location and celerity at any time $t$. However, they are only valid if the dam break wave has traveled more than four times the reservoir length and that the free surface is parallel to the bottom of the sloping channel (Hunt 1982, 1984; Chanson 2004b).

The analytical solution of Eq. (2) is compared with the asymptotic solution (Hunt 1982), as shown in Fig. 4. Comparison is performed in terms of dimensionless time $t^{*}$ and dimensionless dam break wavefront position $x^{*}$. Overall the agreement between the present analytical solution and the asymptotic solution developed by Hunt is good except for the $t^{*}<15$ condition where the asymptotic solution may underpredict the $x^{*}$ value for a given $t^{*}$.

\section{Flow Resistance}

It can be seen from Eq. (5) that once the friction factor $f_{s}$ is determined, the wavefront celerity and location can be computed using Eqs. (8), (9), and (14). Therefore, it is necessary to first understand how the friction factor for stepped chute, $f_{s}$, is associated with flow and boundary conditions.

Previous researchers have focused mainly on skimming flow to evaluate the stepped sloping channel resistance $f_{s}$. Based on published experimental data, Chamani and Rajaratnam (1999a) proposed a log formula that is similar to the equation used for traditional open channels, except that the water depth should be replaced by the one of aerated flow, where air concentration is 0.9. Since then a similar expression has also been developed by Chanson (2002). Unfortunately, the information on $f_{s}$ in the nappe flow region is lacking in the literature. As an approximation, $f_{s}$ may be 
related to the high-gradient stream resistance factor $f_{h}$, which may be computed as

$$
f_{h}=\frac{8 g r S}{V^{2}}
$$

where $f_{h}=$ dimensionless Darcy-Weisbach friction coefficient; $r=$ hydraulic radius $(\mathrm{m}) ; V=$ velocity $(\mathrm{m} / \mathrm{s}) ;$ and $S=$ bed slope. This equation is used because of its wide use in the literature, its dimensionless property, and its compatibility with empirical flowresistance equations. For wide and shallow channels, $r$ equals the water depth $h$, so Eq. (15) can be rewritten as (Chow et al. 1988; Yen 2002)

$$
f_{h}=\frac{8 g h S}{V^{2}}
$$

Emmett (1970) extensively measured the friction resistance factor $f_{h}$ for high-gradient open channels over a wide range of Reynolds numbers in smooth and rough rectangular open channels that both were $1.22 \mathrm{~m}$ wide, $7.62 \mathrm{~cm}$ deep, and $4.88 \mathrm{~m}$ long. The channel bed slope ranged from 3.3 to $77.5 \%$. These measurements remain the benchmark in hydraulic engineering and have served as a crucial database for verifying many formulations proposed for flow resistance. Fig. 5 shows measured $f_{h}$ from these data plotted against Reynolds number $\mathrm{R}$; also superimposed in this figure are the exponential relationships for both laminar and turbulent flow regions for popular open channel flows. Fig. 5 shows that $f_{h}$ decreases rapidly with increasing $\mathrm{R}$ for both laminar and turbulent flow conditions. Unlike the popular open channel flows, all the experimental data points of high-gradient open channel flows cannot merge into a single line. However, comparison between experimental data and the popular open channel friction factor formula gives $f_{h}=96 / \mathrm{R}$ for laminar flow and $f_{h}=0.316 / \mathrm{R}^{0.25}$ (Blasius equation) as the lower limit; this supports Jarrett (1984) that slope has a strong influence on the resistance for high-gradient open channel flows. It can also be seen that the friction factor $f_{h}$ is larger for rough beds than that for smooth surfaces, which indicates that the effect of roughness cannot be neglected for high-gradient open channel flows.

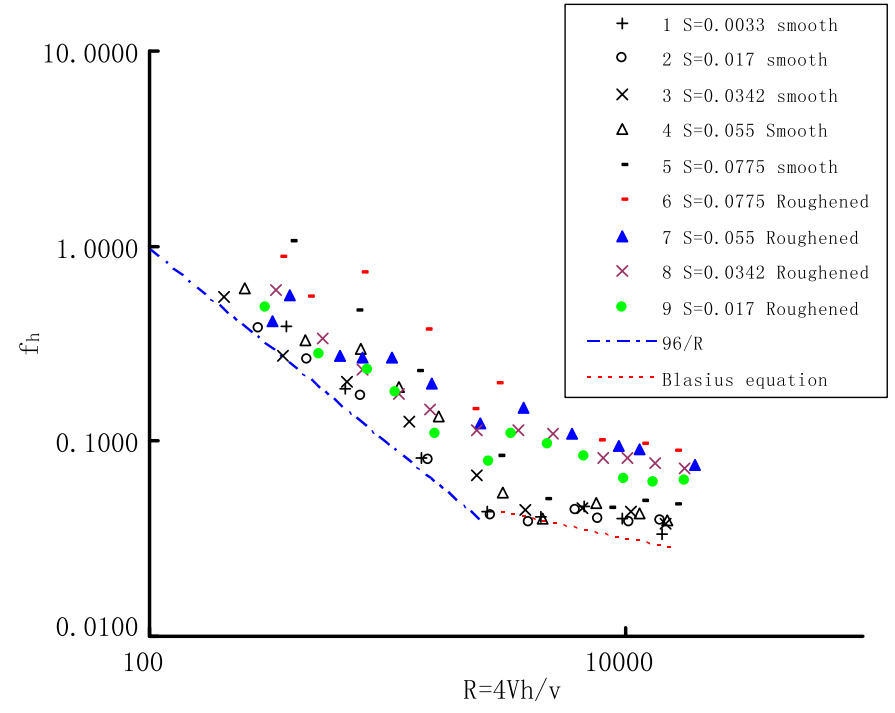

Fig. 5. High-gradient stream friction factor $f_{h}$ as a function of Reynolds number and bed slope (data from Emmett 1970)
Based on the preceding analysis, it can be assumed that the friction factor in the Darcy-Weisbach form is

$$
f_{h 1}=\frac{96+k_{1} S^{m_{1}}+k_{2}\left(\frac{d_{s}}{h}\right)^{m_{2}}}{\mathrm{R}}
$$

for laminar flows and

$$
f_{h 2}=\frac{0.316+k_{3} S^{m_{3}}+k_{4}\left(\frac{d_{s}}{h}\right)^{m_{4}}}{\mathrm{R}^{0.25}}
$$

for turbulent flow. Here $k_{1}, k_{2}, k_{3}, k_{4}, m_{1}, m_{2}, m_{3}$, and $m_{4}$ are the constants to be determined. For small slope and smooth bed channel flows, Eqs. (17) and (18) revert to the popular open channel flow resistance factor formula. Comparison of Eqs. (17) and (18) with the Emmett (1970) data yields that $k_{1}=9,000, m_{1}=1.5$, $k_{2}=150, m_{2}=1, k_{3}=m_{3}=0.2, k_{4}=2.4$, and $m_{4}=0.7$, as presented in Fig. 6, which shows that Eqs. (17) and (18), as expected, represent the data points well.

The friction factor formula, based on Eqs. (17) and (18), is a piecewise function that is inconvenient to use in practice. Also, for practical purposes, such as computer applications, a single equation that applies for all flow regimes is preferable. To get a uniform formula for friction factor for all flow regimes, the key is to get the transition formula based on Eqs. (17) and (18); this led to deploying an interpolation method to formulate an analytical relationship between $f_{h}, \mathrm{R}, d_{s} / h$, and $S$. The interpolation method has been described by Cheng (2008), and thus the following formulations are directly provided without detailed derivations. The transition formula between Eqs. (17) and (18) can be given by

$$
f_{h}=f_{h 1}^{p} f_{h 2}^{1-p}
$$

where $p=$ weighting factor and can be considered as the probability of the contribution of laminar flow and its transition component to friction; and $1-p=$ probability of the contribution of turbulent component. At $p=1$, the flow remains in the laminar regime and switches to the turbulent flow regime at $p=0$. Based on this analysis, the following conditions can be obtained:

$$
p=\frac{1}{1+\left(\frac{\mathrm{R}}{k_{5}}\right)^{m_{5}}}
$$

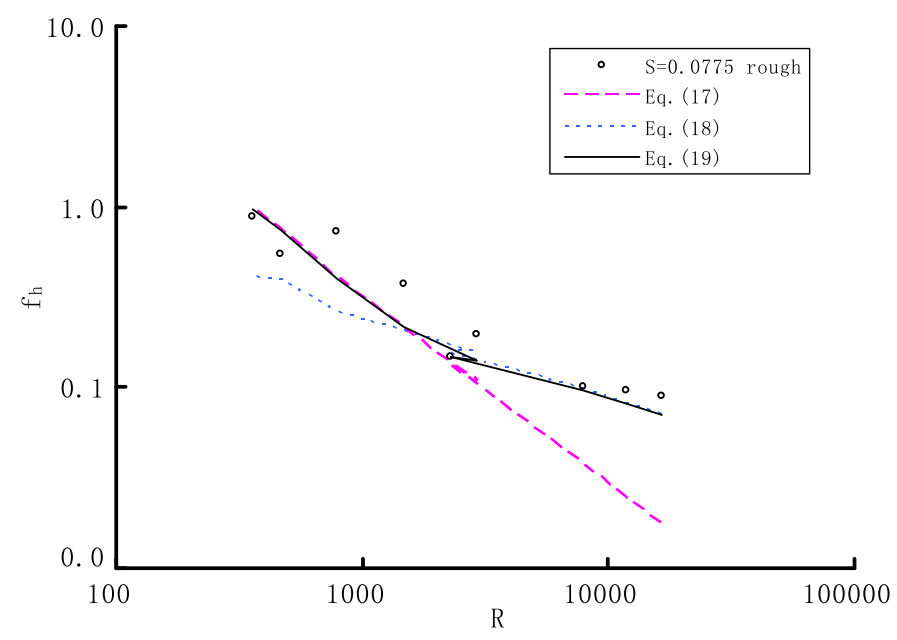

Fig. 6. Comparison of computed friction factor with Emmett's (1970) measurements 
where $k_{5}$ and $m_{5}$ are both constants. The $k_{5}$ and $m_{5}$ values can be evaluated by comparing Eqs. (19) and (20) with the experimental data of Emmett (1970) $\left(S=0.0775\right.$, rough bed). This yields $k_{5}=$ 2,000, and $m_{5}=2$. Fig. 6 also shows a comparison of the measured data points and the computed friction factor values using Eq. (19). This figure shows that the proposed uniform formula fits the experimental data quite well.

The second set of data is by Phelps (1975), who made measurements in a 91.4-cm-wide, 9.74-m-long rough open channel with the measured energy slope $S$ ranging from 6.12 to $45.1 \%$. Fig. 7 compares all the data compiled by Phelps and Emmet with the friction factor computed by Eq. (19) and the agreement is found reasonable.

To present the friction factor of stepped open channels, a parameter $S_{p}$ was introduced, which may be used to describe the degree of development of the stepness. As shown in Fig. 8(a), parameter $S_{p}$ was defined as the ratio of the length of the curve ABCDEFGHIJKLMNOPQ to the length of the straight line AQ minus 1 , i.e.

$$
S_{p}=\frac{\mathrm{AB}+\mathrm{BC}+\mathrm{CD}+\mathrm{DE}+\mathrm{EF}+\mathrm{FG}+\mathrm{GH}+\mathrm{HI}+\mathrm{IJ}+\mathrm{JK}+\mathrm{KL}+\mathrm{LM}+\mathrm{MN}+\mathrm{NO}+\mathrm{OP}+\mathrm{PQ}}{\overline{\mathrm{AQ}}}
$$

For a flat bed, $S_{p}=1$ and for present experiments $S_{p}=1.123$, as will be presented subsequently. Analysis of the observation by Sanchez and Dolz (2005), Zare and Doering (2012), and Wang et al. (2009) has shown that the development of step sequence increases the flow resistance, consumes energy, and protects the streambed from erosion. However, Wang et al. (2004, 2009) show that Manning's roughness coefficient $n$ increases linearly with the degree of stepness $S_{p}$. For the Darcy friction factor, therefore, it is reasonable to assume that

$$
f_{s}=S_{p}^{2} f_{h}
$$

For a flatbed $\left(S_{p}=1\right) f_{s}=f_{h}$, Eq. (21) automatically reverts to the high-gradient open channel flow-resistance formula.

\section{Experimental Setup}

To compare the formulas derived for flood wavefront location and celerity with data that contain different flow and bed surface conditions, experiments were conducted using smooth and rough tilting flumes under various flow conditions. Experiments were conducted in a tilting flume $20 \mathrm{~m}$ long, $0.5 \mathrm{~m}$ wide, and $0.5 \mathrm{~m}$ high at the State Key Laboratory of Hydraulics (SKLH) of Sichuan University. The channel slope was $S=0.135$ (i.e., $\theta=7.77^{\circ}$ ). The water circuit, being a closed system, consisted of a reservoir, a pump, a piece of pipeline, and a controlling valve. The outlet and the inlet structure of the flume were connected to a hydraulic circuit allowing a continuous recirculation of stable discharge.

The flume consisted of eight $0.04 \mathrm{~m}$ high, $0.3 \mathrm{~m}$ long flat steps as shown in Fig. 8 and experiments were composed of two parts: the first part, with the first set of experiments (Series 1), aimed at studying the surging waters down a stepped sloping channel with smooth step surface; the second part, with the second and third sets of experiments (Series 2 and Series 3), aimed at studying the surge water with the roughness generated by grain and stepped configurations. For each series, three kinds of discharge, $Q=0.0000756,0.00128$, and $0.00156 \mathrm{~m}^{3} / \mathrm{s}$, were used, and four measuring sections, located at $x_{s}=1.5,1.8,2.1$, and $2.4 \mathrm{~m}$, respectively, measured from the flow entrance as shown in Fig. 8, were designed. Relevant parameters are listed in Table 1.

In Series 1 (smooth step channel), the step bed surface was smooth and measurements were done as follows: Prior to the start of each experiment, the recirculation pipe system was emptied and the channel was initially dry. Then the pump was rapidly started, and the water entered the reservoir with constant flow rate $Q$. Two observers were used to help conduct the experiments; Observer 1 stood at the front of the reservoir, and Observer 2 was in the front of the measured section [ith step end shown in Fig. 8(a)]. When Observer 1 lowered the reservoir gate and let the flow enter the stepped chute, Observer 2 started recording the time. When the front surge arrived at the test section, Observer 2 stopped recording.

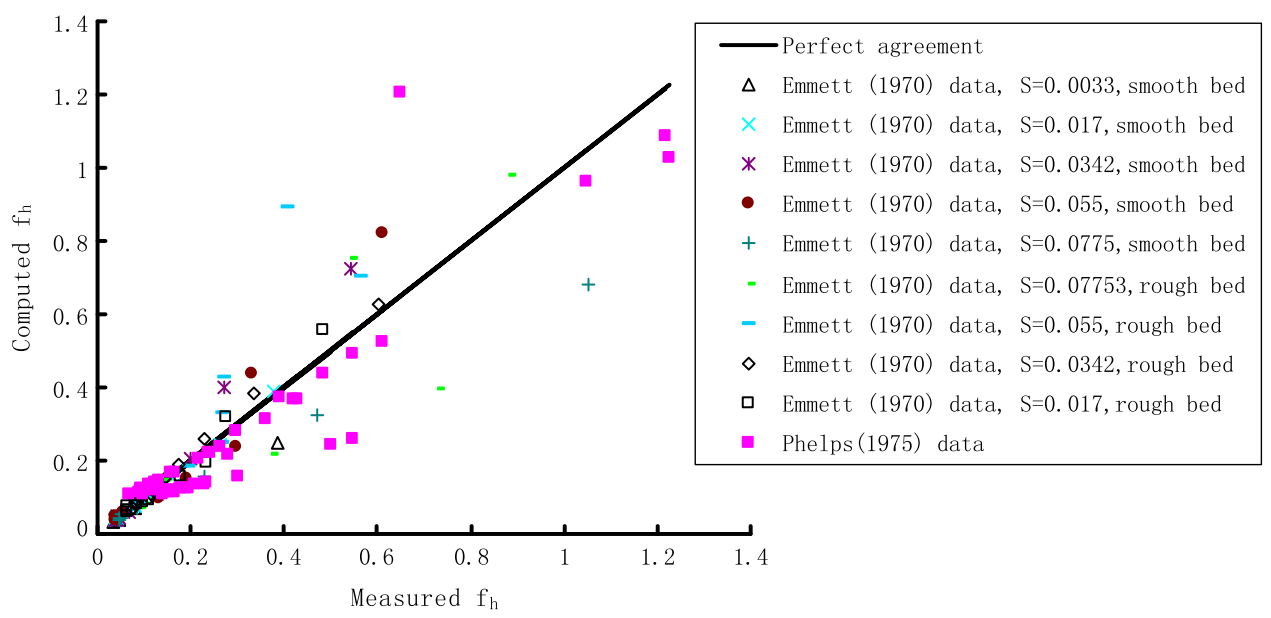

Fig. 7. Comparisons of measured and computed friction factor for high-gradient open channel flows (data from Phelps 1975, (C) ASCE) 


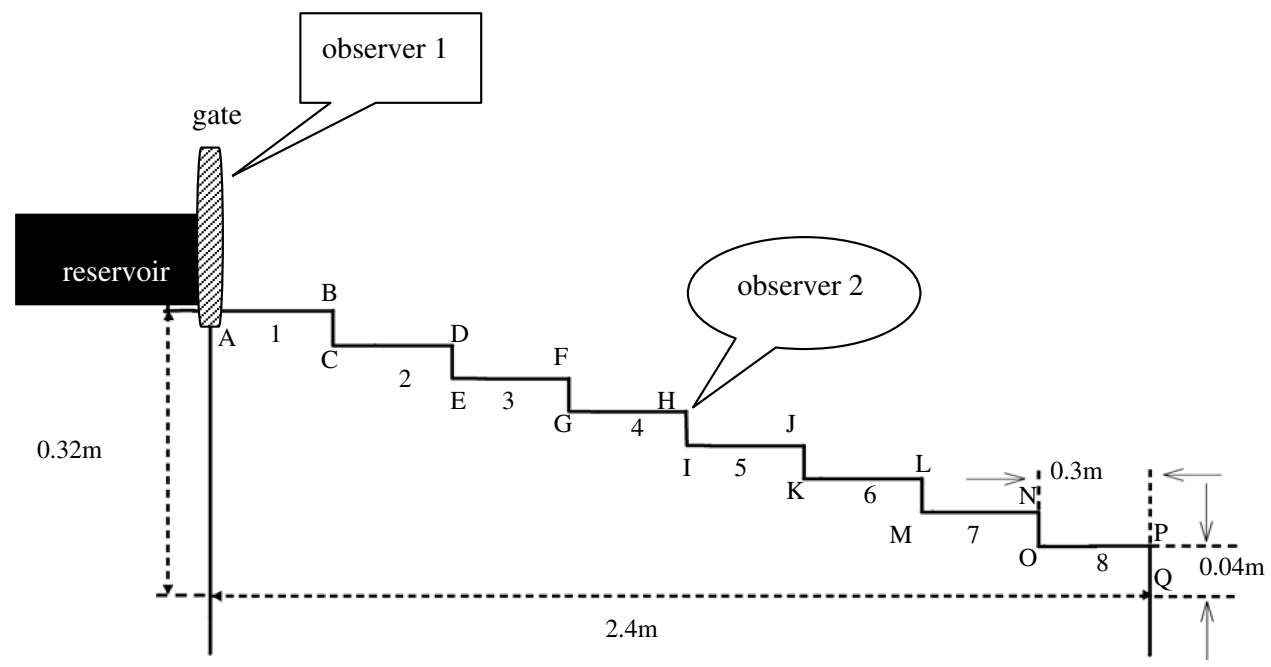

(a)

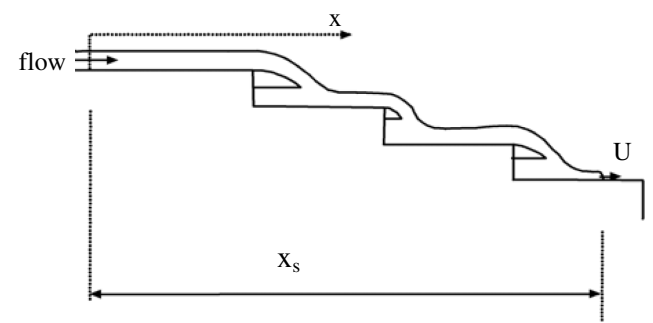

(b)

Fig. 8. General view of experimental setup for (a) stepped open channel; (b) wavefront propagation

Table 1. Summary of Surge Experiments

\begin{tabular}{|c|c|c|c|c|c|}
\hline Experiment & $\underset{\left(\mathrm{m}^{3} / \mathrm{s}\right)}{Q}$ & $\begin{array}{c}\text { Initial } \\
\text { channel } \\
\text { condition }\end{array}$ & $\begin{array}{c}d_{0} \\
(\mathrm{~m})\end{array}$ & $f_{s}$ & Remarks \\
\hline Series 1 & $\begin{array}{l}0.000756 \\
0.00128 \\
0.00156\end{array}$ & $\begin{array}{l}\text { Empty } \\
\text { Empty } \\
\text { Empty }\end{array}$ & $\begin{array}{l}0.0139 \\
0.0197 \\
0.0224\end{array}$ & $\begin{array}{l}0.0680 \\
0.0568 \\
0.0537\end{array}$ & Smooth bed \\
\hline Series 2 & $\begin{array}{l}0.000756 \\
0.00128 \\
0.00156\end{array}$ & $\begin{array}{l}\text { Empty } \\
\text { Empty } \\
\text { Empty }\end{array}$ & $\begin{array}{l}0.0139 \\
0.0197 \\
0.0224\end{array}$ & $\begin{array}{l}0.1963 \\
0.1557 \\
0.1420\end{array}$ & $\begin{array}{l}\text { Bed was glued } \\
\text { with uniform } \\
\text { sediment, } \\
d_{s}=1.715 \mathrm{~mm}\end{array}$ \\
\hline Series 3 & $\begin{array}{l}0.000756 \\
0.00128 \\
0.00156\end{array}$ & $\begin{array}{l}\text { Empty } \\
\text { Empty } \\
\text { Empty }\end{array}$ & $\begin{array}{l}0.0139 \\
0.0197 \\
0.0224\end{array}$ & $\begin{array}{l}0.2344 \\
0.1974 \\
0.185\end{array}$ & $\begin{array}{l}\text { Bed was glued } \\
\text { with uniform } \\
\text { sediment, } \\
d_{s}=3.5 \mathrm{~mm}\end{array}$ \\
\hline
\end{tabular}

Hence, one can get the duration $t_{i}$, where $i$ is the step number shown in Fig. 8(a), the front surge traveling distance $x_{s}$ could be known from the experimental setup, and the wavefront celerity could be expressed as $L /\left(t_{i}-t_{i-1}\right)$, where $L$ is the step length. In Series 2 and Series 3, the stepped bed was covered by two different types of uniform sediment, with sediment diameter $d_{s}=$ $1.715 \mathrm{~mm}$ and $d_{s}=3.5 \mathrm{~mm}$, respectively, and the experimental procedures were the same as those for Series 1. In order to reduce errors, the measurement should be carried out by repeating as many times as possible. However, it was seen that repeating more than 10 times did not improve the precision significantly. Thus, it was decided to repeat the measurement 10 times for each discharge.
The 10 values, obtained for the same discharge and same bed configuration, were then averaged. These averaged values were smoothed mathematically.

\section{Results and Discussion}

Fig. 9 presents the variation of dimensionless location of wavefront $x_{s} / d_{0}$ and dimensionless wavefront celerity $U / \sqrt{g \times d_{0}}$ as a function of dimensionless time $V_{H} \times S \times t / d_{0}$ for different discharges. Eqs. (8) and (9), which constitute relations of dimensionless celerity and location of wavefront with dimensionless time for the stepped sloping open channel flow, respectively, are also graphed in Fig. 9. For a constant discharge $Q$, the data of front location $x_{s} / d_{0}$ merge into a single curve for smooth and rough step conditions; this indicates that the step surface condition does not have a significant influence on $x_{s} / d_{0}$. However, wavefront celerity $U / \sqrt{g \times d_{0}}$ decreases with increasing resistance coefficient $f_{s}$, reflecting the energy loss dissipated by the geometric stepness and the grain glued on the bed surface. For smooth step surface conditions, the average dimensionless wavefront celerity was 1.5 for a larger flow rate of $Q=1.56 \mathrm{~L} / \mathrm{s}$, while it reached a value of 1 for smaller flow rates of $Q=0.756 \mathrm{~L} / \mathrm{s}$ and $Q=1.28 \mathrm{~L} / \mathrm{s}$; however, the results are not consistent with the observation of Chanson (2004b), who stated that the celerity was relatively uniform with the average value approaching 1.5. This difference may be because the present experiments were conducted under the nappe flow condition with short stepped open channel (2.4 m long) and it is believed that nappe flow situations can dissipate higher energy than skimming flow regime on short chutes. 

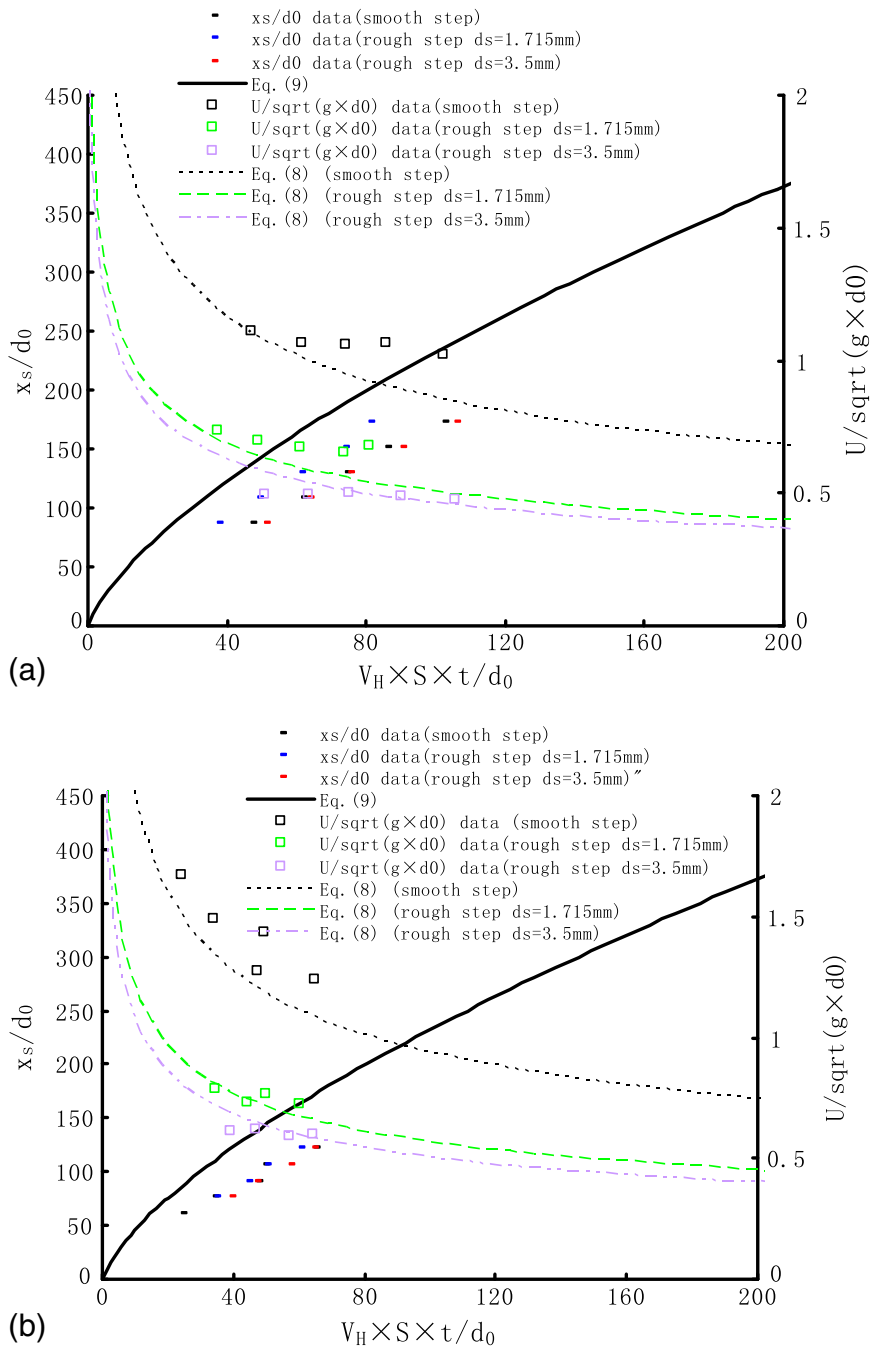

(b)

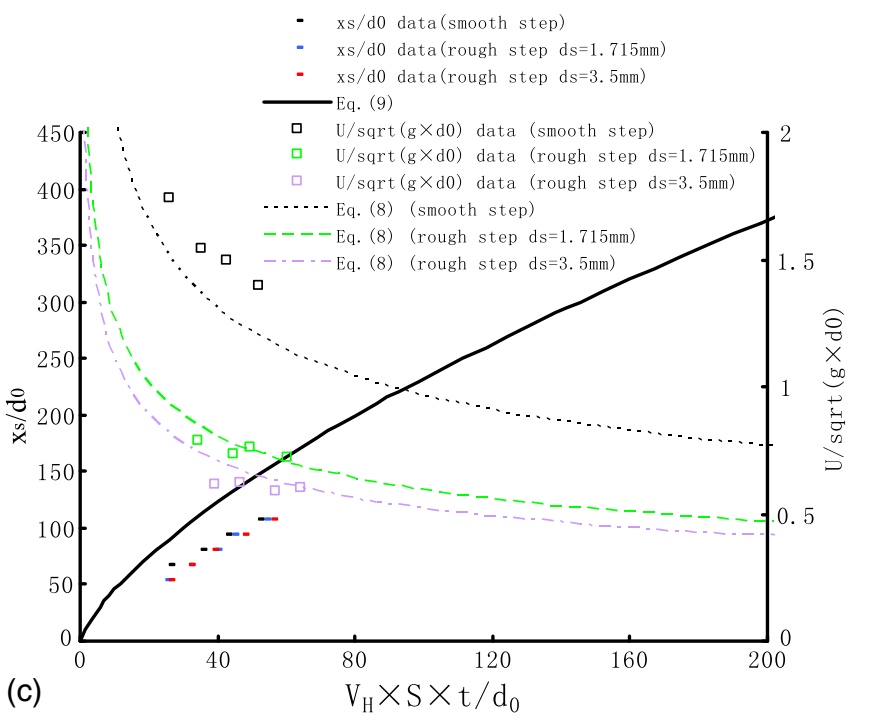

Fig. 9. Propagation of the surge front for dimensionless wavefront location and wavefront celerity: (a) $Q=0.756 \mathrm{~L} / \mathrm{s}$; (b) $Q=1.28 \mathrm{~L} / \mathrm{s}$; (c) $Q=1.56 \mathrm{~L} / \mathrm{s}$

The plotted experimental points all lie under the curve defined by Eq. (9), signifying that the theory may overpredict the wavefront location. Regression of the experimental data indicates that the average standard error of Eq. (9) was $40.4 \%$ and ranged from

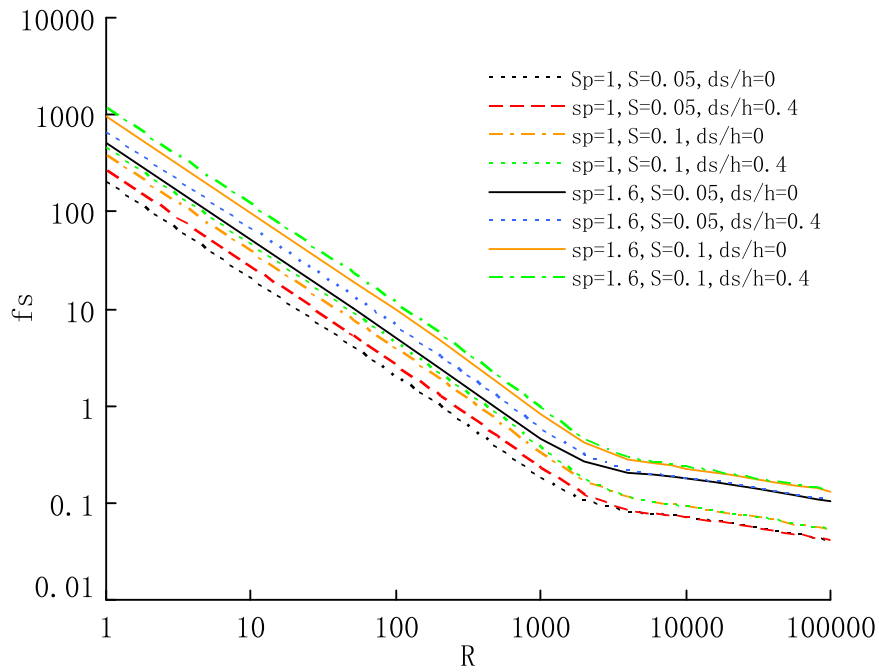

Fig. 10. Variation of friction factor in stepped open channel flow computed using Eq. (21) for $S=0.05,0.1 ; S_{p}=1,1,6$; and $d_{s} / h=0,0.4$

15.6 to $67.7 \%$ for the present experimental data. For the celerity computed by Eq. (8), the average standard error was $13.6 \%$ and ranged from 1.1 to $20.8 \%$. There are several explanations for the errors associated with the flood wavefront location and celerity.

One reason for large errors is the friction factor $f_{s}$ for stepped channel flows. Eq. (21) has been developed for conditions of uniform flow in which the water-surface slope and energy gradient are parallel to the channel bed, and the flow velocity and depth remain relatively constant throughout the channel reach. For lack of a better solution, it is assumed that the equation is also valid for the present unsteady flow because the variation is small in the present study between the maximum and minimum values. Perhaps this assumption adds uncertainty to the final results.

The variation in $f_{s}$ computed using Eq. (21) is plotted in Fig. 10. To compare Eq. (21) with measured data, a database with wide ranges of diameter of sediment covered in the step surface to the water depth ratio $d s / h, \mathrm{R}$, and $S_{p}$ for stepped channel flows is needed but not available at the current stage. Perhaps a correction constant should be added and Eq. (21) is hence rewritten in the form

$$
f_{s}=B^{S_{p}-1} S_{p}^{2} f_{h}
$$

where $B=$ correction constant and can be determined from measurements. By analyzing the present and Chanson (2004b) data for the nappe flow regime, it was discovered that

$$
B=\left[3.5\left(\frac{d_{s}}{d_{0}}\right)^{0.05}+1\right]^{2}
$$

is suitable for the stepped open channels. Eq. (23) shows that unlike skimming flow, the roughness condition of step surface in the nappe flow regime influences the friction factor $f_{s}$. Results showed that the friction factor increases with relative roughness height $\left(d_{s} / d_{0}\right)$.

Another reason that can be attributed to the derivation of Eqs. (8) and (9), which is based on the assumption that the dam break wave travels more than four times the reservoir length and the free surface is parallel to the bottom of the sloping channel. As Chanson stated, large slopes may also cause large errors because Eq. (8) is derived under popular channel slope conditions. Because the 
estimated errors are large, a revised coefficient is necessary. The following is therefore tried:

$$
\begin{gathered}
\left(\frac{x_{s}}{d_{0}}\right)_{r}=\frac{x_{s}}{A_{1} d_{0}} \\
\left(\frac{U}{V_{H}}\right)_{r}=-\frac{3}{4} \times\left(A_{2} \frac{V_{H} \times S \times t}{d_{0}}\right) \\
+\sqrt{1+\left(\frac{x_{s}}{d_{0}}\right)_{r} \times S+\left(\frac{3}{4} \times A_{2} \frac{V_{H} \times S \times t}{d_{0}}\right)^{2}}
\end{gathered}
$$

where $\left(x_{s} / d_{0}\right)_{r}$ and $\left(U / V_{H}\right)_{r}=$ revised values of $x_{s} / d_{0}$ and $\left(U / V_{H}\right)_{r}$, respectively; $A_{1}$ and $A_{2}$ are both correction factors to be determined. It can be seen that once $A_{1}$ and $A_{2}$ are determined, the flood wavefront location and celerity for any time can be computed using Eqs. (24) and (25). Comparison of Eqs. (24) and (25) with the present experimental data yields

$$
\begin{aligned}
& A_{1}=1.3+2.3 e^{-0.1\left[\left(V_{H} \times S \times t\right) / d_{0}\right]} \\
& A_{2}=0.75+e^{-0.18\left[\left(V_{H} \times S \times t\right) / d_{0}\right]}
\end{aligned}
$$

The procedure for computing the nappe flow front location and celerity is now outlined as the following steps:

1. Ensure that the data are in the nappe flow regime using the Ohtsu et al. (2001) method (Fig. 11);

2. Compute water depth $d_{0}$ with Eq. (4);

3. Compute the friction factor $f_{h}$ using Eqs. (17)-(20), then, for stepped open channel flows, the friction factor $f_{s}$ can be computed with Eqs. (22) and (23); here $d_{0}$ is used instead of $h$ because it is difficult to determine $h$ for nappe flow in stepped open channels;

4. Apply Eq. (5) to determine the uniform equilibrium flow velocity $V_{H}$;

5. Determine the two correction coefficients $A_{1}$ and $A_{2}$ with Eq. (26);

6. Calculate $\left(x_{s} / d_{0}\right)$ using Eqs. (9), (14), and (24); and

7. Calculate $U / V_{H}$ using Eq. (25).

Data from Chanson (2004b) and the present study were used to determine whether Eqs. (24) and (25) produced reasonable results and their range of applicability. The wavefront location and celerity estimated, using present equations and the Chanson (2004b)

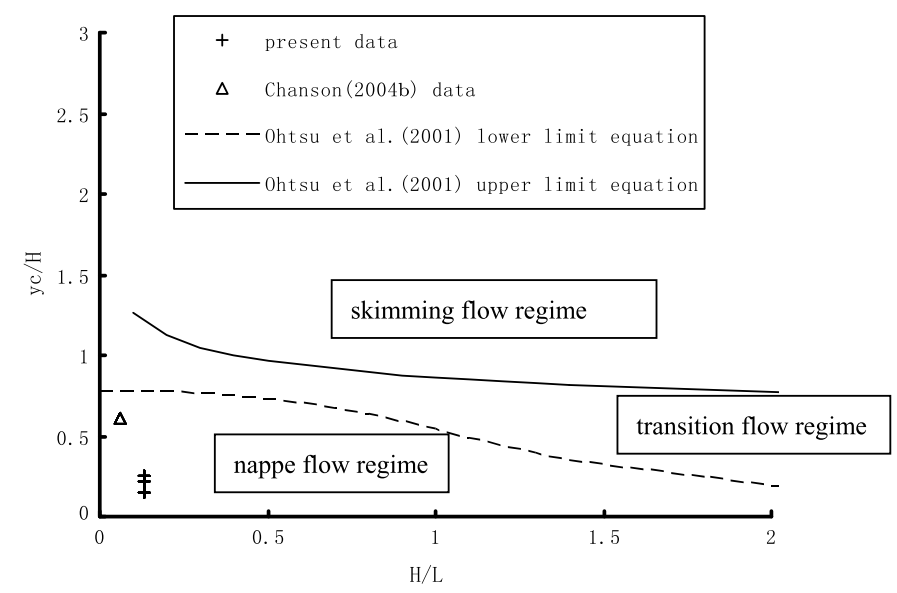

Fig. 11. Classification of flow regimes using Ohtsu et al.'s (2001) method equations, were compared with the measured values (Fig. 12). In general, the derived Eqs. (24) and (25) predicted the location and celerity quite well both for the present and Chanson (2004b) measurements. The Chanson (2004b) equation for the wavefront location overpredicted for the entire range of measurements; the Chanson (2004b) equation overpredicted the wavefront celerity, except for the present smooth surface experimental data points.

The average and maximum errors obtained using the derived equations and the Chanson (2004b) equations are summarized in Table 2. The original Chanson (2004b) equation predicted the location values with an average error of $89.2 \%$ and the overestimation could be up to $186.1 \%$ for the present rough step surface experimental data; large errors were also caused by his wavefront celerity formula. Large errors imply that the original Chanson formula failed to accommodate rough step surface conditions. His prediction was improved for smooth step surface measurements. However, his predicted values were generally overestimated, in particular the location values. In comparison with all the measurements, the derived equations [Eqs. (24) and (25)] provided the best prediction for both the wavefront location and celerity, with an average error, respectively, of 7 and $9.1 \%$ for present smooth surface measurements, 9.8 and $6.7 \%$ for present rough surface measurements, and 8.9 and $10.1 \%$ for the Chanson (2004b) smooth surface measurements. Fig. 13 shows the distribution of errors in the flood wavefront propagation predicted by Eqs. (24) and (25).

Although the errors computed with present model are further reduced, a little scatter is still observed in Fig. 12(c), the scatter is generated as follows. The assumption is that the flood wave equation [Eq. (2)] is used as a basis for the theoretical model. The differential equation is applicable for the condition that the bed is flat and water free surface is parallel to the bottom of the sloping channel; as for stepped channel flows, deviation may be observed. Another reason is that in the experiment flow, the stable water surface is not formed when flood wavefront reaches the observed step, so perhaps the flow should be treated as unsteady flow. The same phenomenon is also observed by Chanson (2004b).

\section{Conclusions}

This paper presents a semiempirical model to predict the flood wavefront propagation down a rough stepped sloping channel based on Hunt's (1982) differential equation; the present work aims at nappe flow regime. First, an analytical solution of the ordinary differential equation due to Hunt (1982) is derived. It shows that the dimensionless wavefront position depends only on the dimensionless travel time. Comparison with the asymptotic solution developed by Hunt (1982) shows that both are in good agreement with each other, except that the asymptotic solution may underpredict the dimensionless position when the dimensionless time is less than 15 .

Calculation of flood wavefront propagation in stepped open channels requires an evaluation of channel roughness. Deploying an interpolation approach, a single explicit formula is developed for computing the stepped open channel flow friction factor in the nappe flow regime. Unlike popular open channel flows, as for a given Reynolds number $\mathrm{R}$, the stepped open channel flow roughness $f_{s}$ in the nappe flow regime increases with slope $S$, parameter $S_{p}$, and the step surface roughness $d_{s} / d_{0}$.

Experiments are conducted to test the surge propagation in stepped open channels. A smooth stepped open channel and two kinds of rough stepped flumes were used in the experiments. The results show that for a given discharge $Q$, the front location 

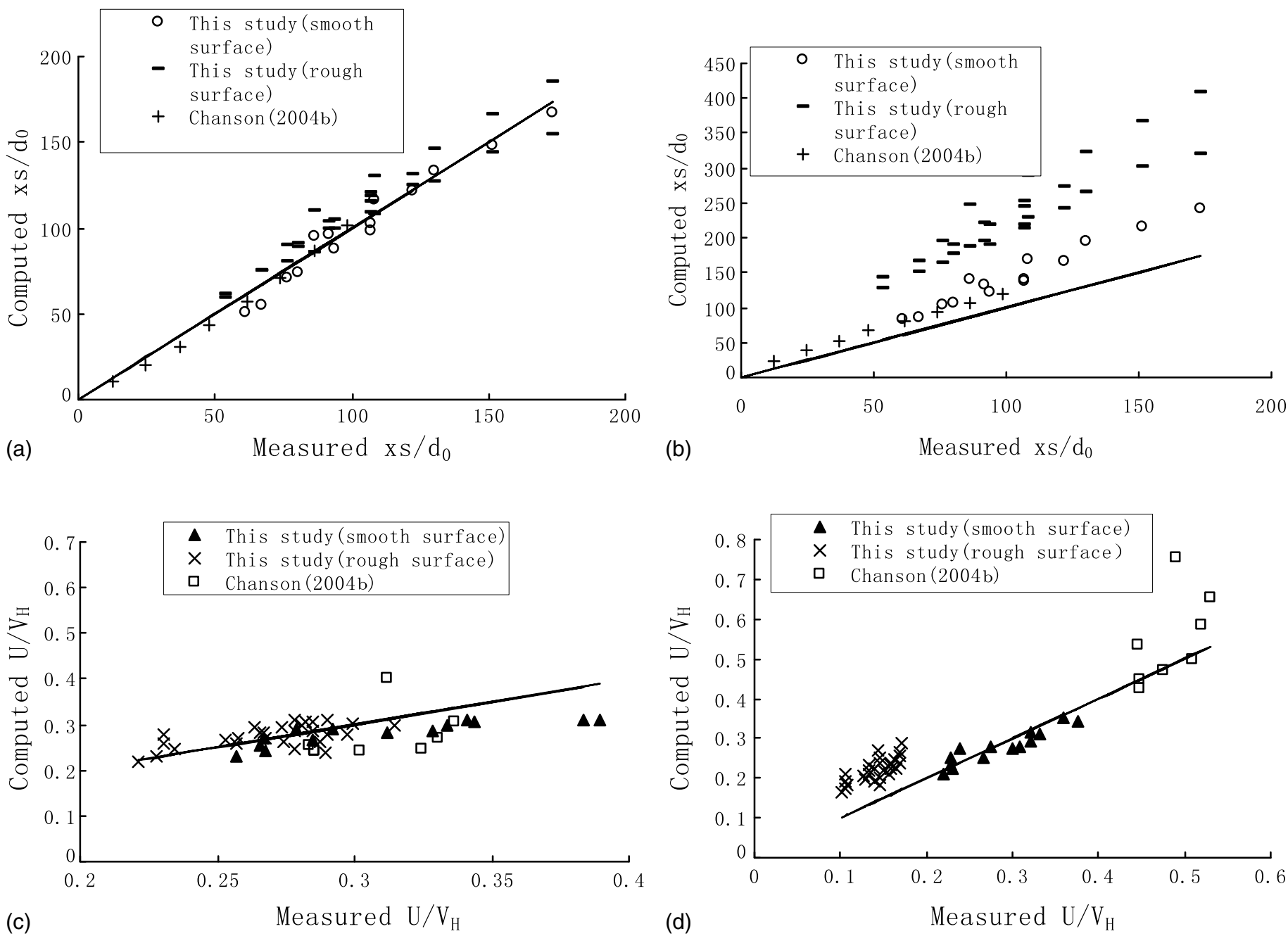

Fig. 12. Comparison of measured and predicted values of wavefront location and celerity: (a) wavefront location computed with Eq. (24); (b) wavefront location computed with Chanson (2004b) model; (c) wavefront celerity computed with Eq. (25); (d) wavefront celerity computed with Chanson (2004b)

Table 2. Summary of Errors in Flood Wavefront Propagation Predictions

\begin{tabular}{|c|c|c|c|c|c|c|}
\hline \multirow[b]{2}{*}{ Approach } & \multicolumn{2}{|c|}{$\begin{array}{l}\text { Present measurements } \\
\text { (smooth surface) }\end{array}$} & \multicolumn{2}{|c|}{$\begin{array}{l}\text { Present measurements } \\
\text { (rough surface) }\end{array}$} & \multicolumn{2}{|c|}{ Chanson (2004b) measurements } \\
\hline & Average error & Maximum error & Average error & Maximum error & Average error & Maximum error \\
\hline Chanson (2004b) location model & 0.397 & 0.633 & 1.278 & 1.861 & 0.409 & 0.810 \\
\hline Chanson $(2004 b)$ celerity model & 0.062 & 0.141 & 0.568 & 0.962 & 0.148 & 0.542 \\
\hline Present study, Eq. (24) & 0.070 & 0.183 & 0.098 & 0.276 & 0.089 & 0.174 \\
\hline Present study, Eq. (25) & 0.091 & 0.201 & 0.067 & 0.204 & 0.101 & 0.225 \\
\hline
\end{tabular}

data merge into a single curve both for smooth and rough step conditions. The wavefront celerity decreases with increasing step surface roughness.

Then, the analytical solution is used to calculate the wavefront location and celerity. The comparison with experimental data shows that the analytical solution may overpredict the wavefront location; one reason is that the friction factor $f_{s}$ is developed for conditions of uniform flow in which the water-surface slope and energy gradient are parallel to the channel bed. Another reason can be attribute to Hunt's (1982) differential equation. Because the equation is applicable for the flat bed condition, as for stepped channel flows, deviation may be observed. The unsteady experiment flow also causes the large errors because the stable water surface is not formed when the flood wavefront reaches the observed step, so perhaps the flow should be treated as unsteady flow and a modification is needed. These revised equations apply empirical modifications to either dimensionless time, friction factor, or the constants involved in the original equations. In comparison with Chanson's original equations, the derived equations are applicable for both smooth and rough surfaces, and provide the best location and celerity prediction for the nappe flow condition. 

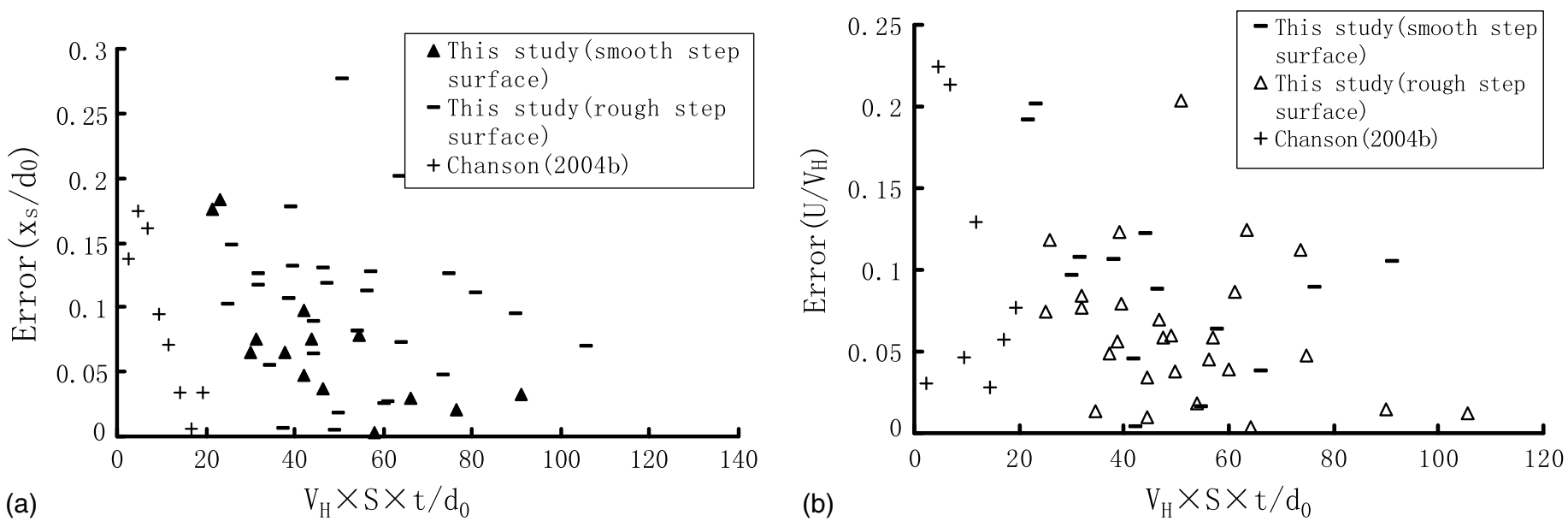

Fig. 13. Distribution of errors in flood wavefront propagation prediction with Eqs. (24) and (25): (a) wavefront location error; (b) wavefront celerity error

\section{Appendix. Analytical Solution of Hunt (1982) Flood Wave Propagation Equation [Eq. (2)]}

Eq. (2) is a kind of implicit first-order differential equation and it is hard to get the solution directly. Because $x^{*}$ is a function of $t^{*}$, it is reasonable to assume

$$
f\left(t^{*}\right)=\sqrt{x^{*}+\left(\frac{3}{4} t^{*}\right)^{2}}
$$

Differentiation of Eq. (27) gives the relation

$$
\frac{d x^{*}}{d t^{*}}=2 f\left(t^{*}\right) \frac{d f\left(t^{*}\right)}{d t}-\frac{9}{8} t^{*}
$$

Substituting Eqs. (27) and (28) into Eq. (2), one obtains

$$
\frac{d f\left(t^{*}\right)}{d t^{*}}=\frac{\frac{3}{16} t^{*}+\frac{1}{2} f\left(t^{*}\right)}{f\left(t^{*}\right)}
$$

The researchers define

$$
Y=\frac{f\left(t^{*}\right)}{t^{*}}
$$

The following equation can be obtained by differentiating Eq. (30):

$$
\frac{d f\left(t^{*}\right)}{d t^{*}}=Y+t^{*} \frac{d Y}{d t^{*}}
$$

Substitution of Eqs. (30) and (31) into Eq. (29) results in

$$
\frac{Y}{\frac{3}{16}+\frac{1}{2} Y-Y^{2}} d Y=\frac{1}{t^{*}} d t^{*}
$$

which gives

$$
-\int \frac{Y}{Y^{2}-\frac{1}{2} Y-\frac{3}{16}} d Y=\int \frac{1}{t^{*}} d t^{*}
$$

The solution of Eq. (33) is

$$
t^{*}=C\left(Y+\frac{1}{4}\right)^{-1 / 4}\left(Y-\frac{3}{4}\right)^{-3 / 4}
$$

where $C=$ constant. Coupled with Eqs. (30) and (34), one can get Eq. (7), where $C_{1}=C^{4}$. Eq. (27) can also be rewritten as Eq. (6). Eqs. (6) and (7) are the analytical solution of propagation equation.

\section{Acknowledgments}

This research was supported by the Key Program of National Natural Science Foundation of China (Grant No. 51639007), the National Key Research and Development Program of China (2016YFC0402302), and the National Natural Science Foundation of China (NSFC) (No. 51279116).

\section{Notation}

The following symbols are used in this paper:

$B=$ correction constant;

$b=$ channel width;

$C, C_{1}=$ constant;

$d_{s}=$ sediment diameter;

$d_{0}=$ reservoir height at the dam site;

$f(\bullet)=$ unknown function;

$f_{h}=$ Darcy-Weisbach friction factor for high-gradient open channel flows

$f_{h 1}, f_{h 2}=$ friction factor $f_{h}$ for laminar and turbulent flows, respectively;

$f_{s}=$ Darcy-Weisbach friction factor for stepped open channel flows;

$g=$ gravitational acceleration;

$H=$ step height $(\mathrm{m})$;

$h=$ water depth $(\mathrm{m})$;

$k_{1}, k_{2}, k_{3}, k_{4}, k_{5}=$ constants;

$L=$ step length;

$m_{1}, m_{2}, m_{3}, m_{4}, m_{5}=$ constants;

$Q=$ initial flow rate;

$\mathrm{R}=$ Reynolds number for open channel flows $(=4 V h / v)$;

$r=$ hydraulic radius;

$S=$ bed slope;

$S_{p}=$ stepped open channel parameter;

$t=$ time;

$t^{*}=$ dimensionless time; 
$U=$ wavefront velocity;

$V=$ mean velocity for high-gradient open channel flows;

$V_{H}=$ uniform equilibrium flow velocity;

$x_{s}=$ dam break wave or flood wavefront location (traveling distance); and

$x^{*}=$ dimensionless wavefront location.

\section{References}

Chamani, M. R., and Rajaratnam, N. (1994). "Jet flow on stepped spillways." J. Hydraul. Eng., 10.1061/(ASCE)0733-9429(1994)120: 2(254), 254-259.

Chamani, M. R., and Rajaratnam, N. (1999a). "Characteristics of skimming flow over stepped spillways.” J. Hydraul. Eng., 10.1061/(ASCE)0733 -9429(1999)125:4(361), 361-368.

Chamani, M. R., and Rajaratnam, N. (1999b). "Onset of skimming flow on stepped spillways." J. Hydraul. Eng., 10.1061/(ASCE)0733-9429 (1999)125:9(969), 969-971.

Chanson, H. (1994a). "Comparison of energy dissipation between nappe and skimming flow regimes on stepped chutes." J. Hydraul. Res., $32(2), 213-218$.

Chanson, H. (1994b). "Hydraulics of nappe flow regime above stepped chutes and spillways." Aust. Civil Eng. Trans., CE36(1), 69-76.

Chanson, H. (2002). The hydraulics of stepped chutes and spillways, A.A. Balkema, Lisse, Netherlands.

Chanson, H. (2004a). "Drag reduction in skimming flow on stepped spillways by aeration." J. Hydraul. Res., 42(3), 316-322.

Chanson, H. (2004b). "Experimental study of flash flood surges down a rough sloping channel." Water Resour. Res., 40(3), W03301.

Chanson, H., and Toombes, L. (2002). "Air-water flows down stepped chutes: Turbulence and flow structure observations." Int. J. Multiphase Flow, 28(11), 1737-1761.

Chanson, H., and Toombes, L. (2004). "Hydraulic of stepped chutes: The transition flow." J. Hydraul. Res., 42(1), 43-54.

Chanson, H., Yasuda, Y., and Ohtsu, I. (2002). "Flow resistance in skimming flows and its modeling." Can. J. Civil Eng., 29(6), 809-819.

Cheng, N. S. (2008). "Formulas for friction factor in transitional regimes." J. Hydraul. Eng., 10.1061/(ASCE)0733-9429(2008)134:9(1357), $1357-1362$.
Chow, V. T., Maidment, D. R., and Mays, L. W. (1988). Applied hydrology, McGraw-Hill, Singapore.

Emmett, W. W. (1970). "The hydraulics of overland flow on hillslopes." Water Supply Paper 662-A, U.S. Geological Survey, Washington, DC.

Hunt, B. (1982). "Asymptotic solution for dam-break problem." J. Hydraul. Div., 108(1), 115-126.

Hunt, B. (1984). "Perturbation solution for dam-break floods." J. Hydraul. Eng., 10.1061/(ASCE)0733-9429(1984)110:8(1058), 1058-1071.

Jarrett, R. D. (1984). "Hydraulics of high-gradient streams." J. Hydraul. Eng., 10.1061/(ASCE)0733-9429(1984)110:11(1519), 1519-1539.

Meireles, I., and Matos, J. (2009). "Skimming flow in the no-aerated region of stepped spillways over embankment dams." J. Hydraul. Eng., 10.1061/(ASCE)HY.1943-7900.0000047, 685-689.

Montes, J. S. (1998). Hydraulics of open channel flow, ASCE, Reston, VA.

Ohtsu, I., Yasuda, Y., and Takahashi, M. (2001). "Discussion on onset of skimming flow on stepped spillways." J. Hydraul. Eng., 10.1061 /(ASCE)0733-9429(2001)127:6(519), 522-524.

Phelps, H. (1975). "Shallow laminar flow over rough granular surfaces." J. Hydraul. Div., 101(3), 367-384.

Rajaratnam, N. (1990). "Skimming flow in stepped spillways." J. Hydraul. Eng., 10.1061/(ASCE)0733-9429(1990)116:4(587), 587-591.

Sanchez, J. M., and Dolz, J. (2005). "Experimental study of transition and skimming flows on stepped spillways in RCC dams: Qualitative analysis and pressure measurements." J. Hydraul. Res., 43(5), 540-548.

Simoes, A. (2010). "Stepped and smooth spillways: Resistance effects on stilling basin lengths." J. Hydraul. Res., 48(3), 329-337.

Tabbara, M., Chatila, J., and Awwad, R. (2005). "Computational simulation of flow over stepped spillways." Comput. Struct., 83(27), 2215-2224.

Walter, W. (1998). Ordinary differential equation, Springer, New York.

Wang, Z. Y., Melching, C. S., Duan, X. H., and Yu, G. A. (2009). "Ecological and hydraulic studies of step-pool systems." J. Hydraul. Eng., 10.1061/(ASCE)0733-9429(2009)135:9(705), 705-717.

Wang, Z. Y., Xu, J., and Li, C. Z. (2004). "Development of step-pool sequence and its effects in resistance and stream bed stability." Int. J. Sediment Res., 19(3), 161-171.

Yen, B. C. (2002). "Open channel flow resistance." J. Hydraul. Eng., 10.1061/(ASCE)0733-9429(2002)128:1(20), 20-39.

Zare, H., and Doering, J. (2012). "Energy dissipation and flow characteristics of baffles and sills on stepped spillways." J. Hydraul. Res., 50(2), 192-199. 